\title{
Monitoreo de la producción de caña panelera mediante herramientas de SIG y teledetección, años 2016-2017, Mérida, Venezuela
}

\section{Monitoring of panelera cane production using GIS and remote sensing tools, 2016-2017 years, Mérida, Venezuela}

\author{
Carlos Enrique Guillén-García ${ }^{1}$ \\ Ministerio del Poder Popular para la \\ Agricultura Productiva y Tierras, Venezuela \\ Amanda Mogollón-Rojo ${ }^{2}$. \\ Universidad de los Andes, Venezuela \\ Mirian Josefina Dávila-Albarrán ${ }^{3}$ \\ Universidad de los Andes, Venezuela \\ Katherina Boscán-Árraga \\ Ministerio del Poder Popular para la \\ Agricultura Productiva y Tierras, Venezuela
}

\section{Resumen}

Actualmente, las metodologías de evaluación de la producción agrícola no permiten realizar un seguimiento o monitoreo para conocer con precisión la producción. El estado Mérida-Venezuela aporta al país más de 515.000 TM en rubros agrícolas. Esto dificulta la captación veraz de la

1 Ing. Agrónomo. Msc. Ministerio del Poder Popular para la Agricultura Productiva y Tierras (MPPAPT). Instituto Nacional de Salud Agrícola Integral-(INSAI), Mérida estado Mérida, Venezuela. guillencarlos41@gmail.com

2 Geógrafa. Universidad de los Andes (ULA), Profesora de la Escuela de Geografía, Mérida estado Mérida, Venezuela.geo.amandamogollon@gmail.com

3 Ing. Forestal. Msc. Universidad de los Andes (ULA), Profesora de la Escuela de Geografía, Mérida estado Mérida, Venezuela.miriandavila@gmail.com

4 Lic. Biología. Msc. Ministerio del Poder Popular para la Agricultura Productiva y Tierras (MPPAPT). Mérida estado Mérida. k_boscan@yahoo.com 
información productiva; por lo cual se están empleando alternativas tecnológicas que las subsanen. Se ha monitoreado la Caña panelera (Saccharum officinarum sp) a través de imágenes satelitales Sentinel 2A, del 27/03/2016 y el 01/04/2017; y procesadas con el software QGIS-2.18. Se emplearon registros agrarios para establecer las áreas de entrenamiento y verificación de la clasificación supervisada. Se identificaron 379 ha del cultivo para el 27/03/2016; y 361 ha para el 01/04/2017. Esta evaluación identificó 51,6 \% más de la superficie (129 ha) obtenida por instituciones oficiales de Mérida para el año 2016, y se estima que superé en más del 50 \% la producción para el año 2017, ya que la institución no había consolidado la información.

Palabras clave: Monitoreo de cultivos, Caña panelera, Saccharum officinarum sp, Teledetección, SIG, Mérida.

\begin{abstract}
Currently, methodologies for evaluating agricultural production do not allow precision tracking or monitoring of the production. The state Merida in Venezuela contributes to the country with more than 515,000 MT in agricultural goods. Lack of the above mentioned methodologies hinder the truthful capture of agricultural production data; alternative technologies are being used to overcome such deficiency. Panelera cane (Saccharum officinarum sp) has been monitored through Sentinel 2A satellite images captured from 27/03/2016 to 01/04/2017; and processed with QGIS-2.18 software. Agrarian records were used to establish training and verification areas of the supervised classification 379 hectares (ha) of crop were identified by 27/03/2016; and 361 ha by 01/04/2017. The present evaluation identified 51.6\% (129 ha) of additional area as that reported by the official institutions of Mérida for the year 2016; production is estimated to exceed by more than $50 \%$ in 2017 because institutions has not consolidated the information.
\end{abstract}

Keywords: Crop monitoring; cane panelera; Saccharum officinarum sp; remote sensing; GIS; Mérida.

\title{
1. Introducción
}

Los pronósticos anticipados a la cosecha aportan información valiosa para estimar la cantidad de alimentos que se requiere complementar, con el fin de afrontar los posibles déficits de producción y abastecer a la población. Actualmente, las metodologías convencionales de captación y evaluación de la producción agrícola no permiten realizar un seguimiento o monitoreo con el que se pueda estimar o conocer con precisión los volúmenes de alimentos que estarán disponibles, ya que la infraestructura con que se cuenta no logra recabar la información necesaria de forma oportuna y veraz, para una correcta planificación y apoyo al campo.

La teledetección juega un papel vital en el análisis de los sistemas de producción agrícola mediante la integración de información espacial y temporal en varios ciclos de cultivo durante el año. La información de los sistemas de producción agrícola, tales como la extensión de los cultivos, 
Carlos Enrique Guillén-García - Amanda Mogollón -Rojo - Mirian Josefina Dávila-Albarrán - Katherina Boscán-Árraga Monitoreo de la producción de caña panelera mediante herramientas de SIG y teledetección,

años 2016-2017, Mérida, Venezuela

vigor y rendimiento, rotación, secuencia en prácticas culturales, entre otras; son importantes para conocer los niveles de rendimiento de las zonas agrícolas (Guillén \& Dávila, 2017).

Los sensores remotos han sido empleados desde hace décadas para evaluar los cambios en las coberturas y usos de la tierra (Chen, Z., 2008, Butt, A. et al, 2015, Farrell, M \& Rivas, R. 2010), cambios que son influenciados por factores físicos, climáticos y socioeconómicos, tanto en el tiempo como en el espacio (Kaliraj, S., et al, 2017). La teledetección es una técnica científica empleada para obtener información sobre objetos o áreas a distancia, típicamente desde aviones o satélites. La detección remota que utiliza sensores espaciales es una herramienta incomparable para obtener observaciones sinópticas y repetitivas de cultivos permanentes, así como de su entorno (Anindya S., 2016). La ventaja de usar esta herramienta es que provee información espectral, espacial y temporal de los objetos que estemos evaluando.

El cultivo de la caña de azúcar es ampliamente producido en las tierras venezolanas. La producción es destinada, principalmente, para producir azúcar refinada en los centrales azucareros. En el estado Mérida, la producción de Caña se concentra en la parroquia San Juan de Lagunillas del municipio Sucre; cosecha que es destinada, aún en su totalidad, a los procesos agroindustriales (trapiches artesanales), cuyo principal producto derivado es la panela; siendo este un producto alimenticio obtenido a partir de la evaporación y concentración de los jugos de la caña de azúcar, utilizado para bebidas o como edulcorante (Mosquera, S., et al, 2007). El presente trabajo busca evaluar mediante herramientas de teledetección y Sistemas de Información Geográficos (SIG) la superficie destinada para la producción de Caña panelera durante los años 2016 y 2017.

\section{Metodología}

Para el desarrollo de la presente investigación se emplearon técnicas de Teledetección y Sistemas de Información Geográficas (SIG), las cuales permitieron identificar y cuantificar las superficies y producción del cultivo de caña panelera en la parroquia San Juan de Lagunillas, Municipio Sucre del Estado Mérida, Venezuela; información que fue integrada a un SIG para su visualización, interpretación, procesamiento y análisis (figura 1). La parroquia presenta un relieve irregular, donde se combinan 
grandes desniveles y terrenos planos, pudiendo diferenciar dos unidades fisiográficas como lo son: los fondos de valle y las vertientes (figuras 2 y $3)$, todo ello producto del control estructural proveniente de la falla de Boconó (Martínez, 1963). La parroquia se caracteriza por presentar un clima semiárido, con precipitaciones media anual de aproximadamente $541 \mathrm{~mm}$, y temperaturas medias anuales de $24^{\circ} \mathrm{C}$. Presenta una variedad de suelos, donde las características de los materiales originarios están relacionados directamente con la geología y geomorfología (Rojas, 1970).

Figura 1. Esquema metodológico seguido para el desarrollo de la investigación.

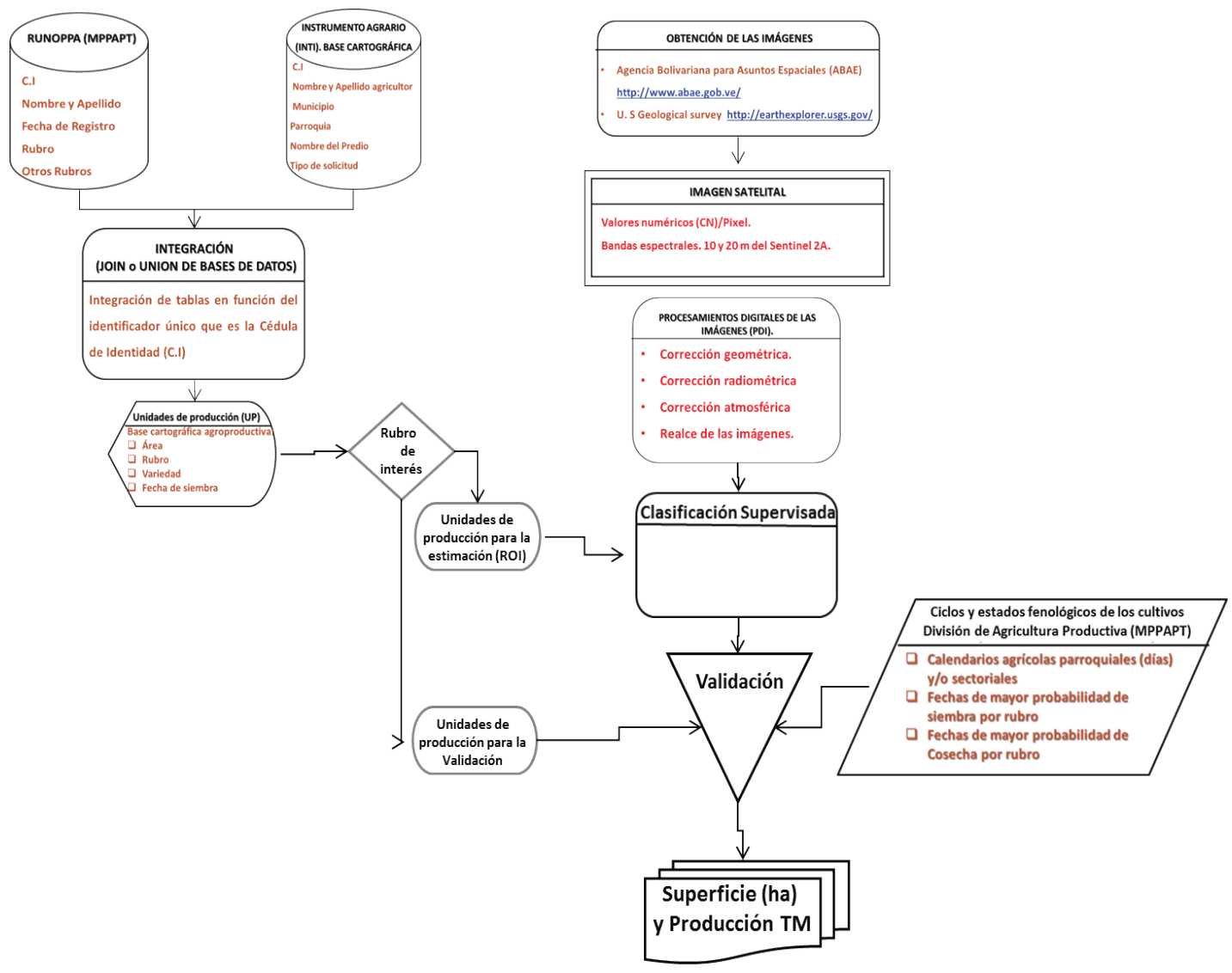


Carlos Enrique Guillén-García - Amanda Mogollón -Rojo - Mirian Josefina Dávila-Albarrán - Katherina Boscán-Árraga Monitoreo de la producción de caña panelera mediante herramientas de SIG y teledetección, años 2016-2017, Mérida, Venezuela

Figura 2. Ubicación relativa del área de investigación.

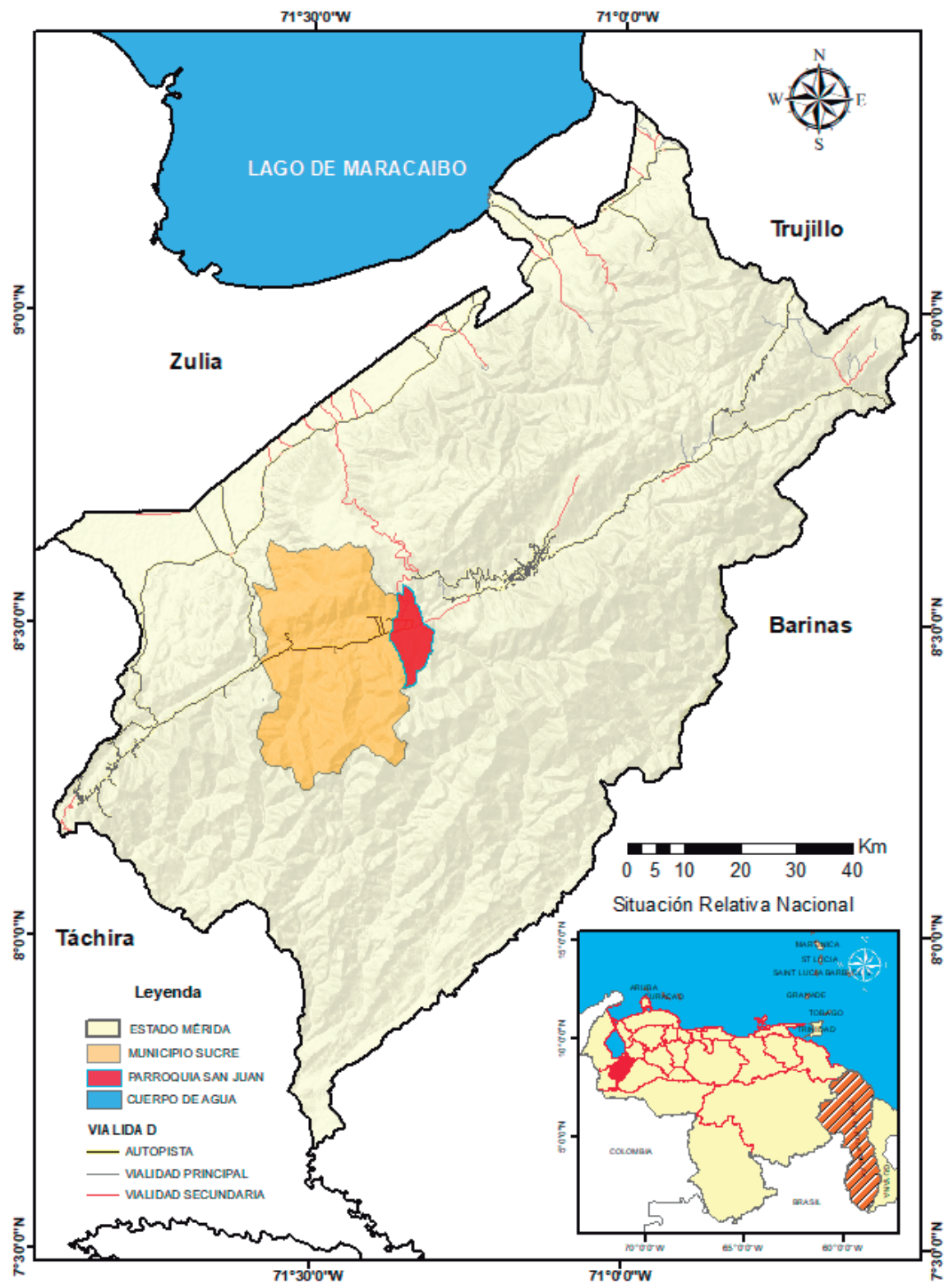

Fuente: Elaborado con base a la cartografía Nacional oficial del IGVSB (2014). 
Figura 3. Ubicación relativa local. Límites de la Parroquia San Juan de Lagunillas.

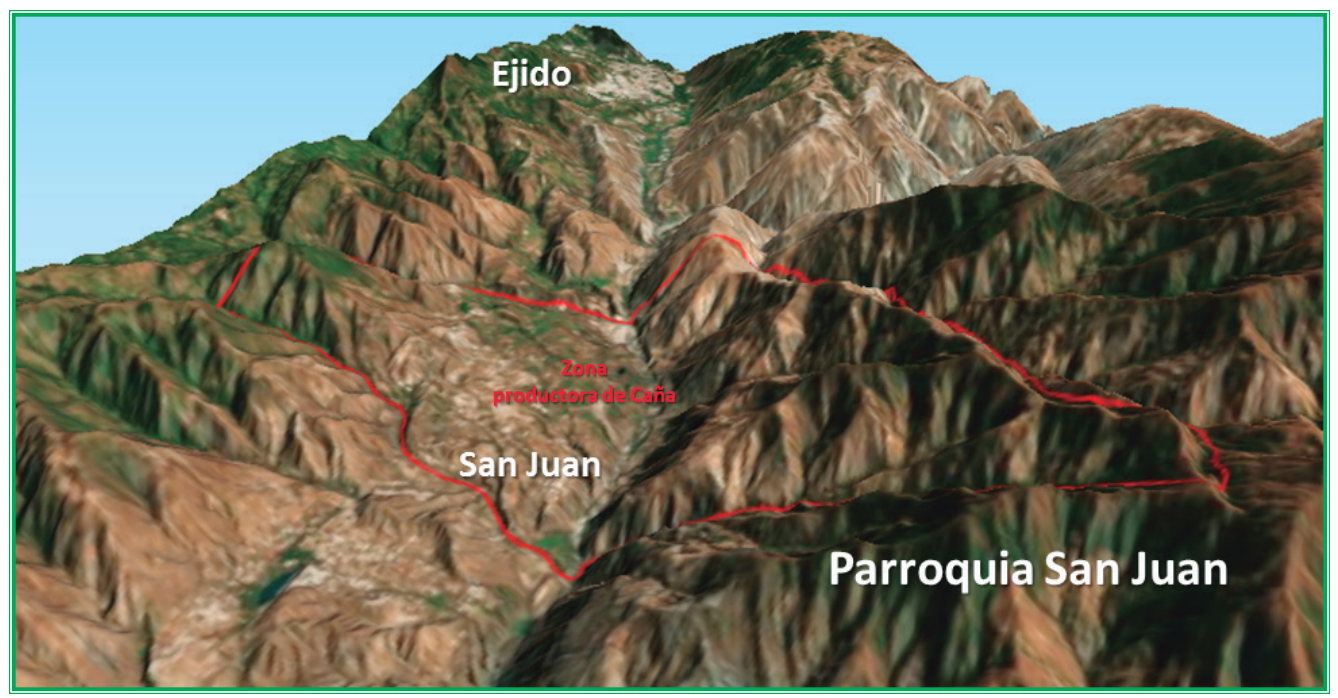

Fuente: Elaboración propia basada en el SRTM (Shuttle Radar Topography Mission) de 1 Arc second global; y la imagen Sentinel 2A combinación 4-3-2 del 17/10/2017 (https://earthexplorer. usgs.gov, 2017)

\subsection{Información base}

\subsubsection{Información agroproductiva}

El cultivo de la caña de azúcar ha sido un cultivo tradicional en Venezuela. Su procesamiento ha venido incrementándose con el aumento de la modernización e industrialización del sector. Para inicios del siglo XXI, Venezuela cuenta con quince centrales azucareros, entre privados y públicos, en diferentes estados de operatividad. La producción de caña se sitúa en diferentes regiones del país; una de ellas, tal vez no destacada por las pequeñas superficies, es la producción de Caña de azúcar para la elaboración de panela de la parroquia San Juan de Lagunillas del Estado Mérida (Figuras 4 y 5); parroquia que cuenta con 20 trapiches con distintos niveles de operatividad. El ciclo de producción de la caña en esta zona, dependiendo de la variedad, oscila entre 10 y 18 meses, con unos rendimientos entre 200 y 800 pacas $(1 \mathrm{Kg}) /$ ha; destacándose la variedad Peineta con 800 pacas/ha. 
Carlos Enrique Guillén-García - Amanda Mogollón -Rojo - Mirian Josefina Dávila-Albarrán - Katherina Boscán-Árraga Monitoreo de la producción de caña panelera mediante herramientas de SIG y teledetección, años 2016-2017, Mérida, Venezuela

Figura 4. Producción panelera en un Trapiche.

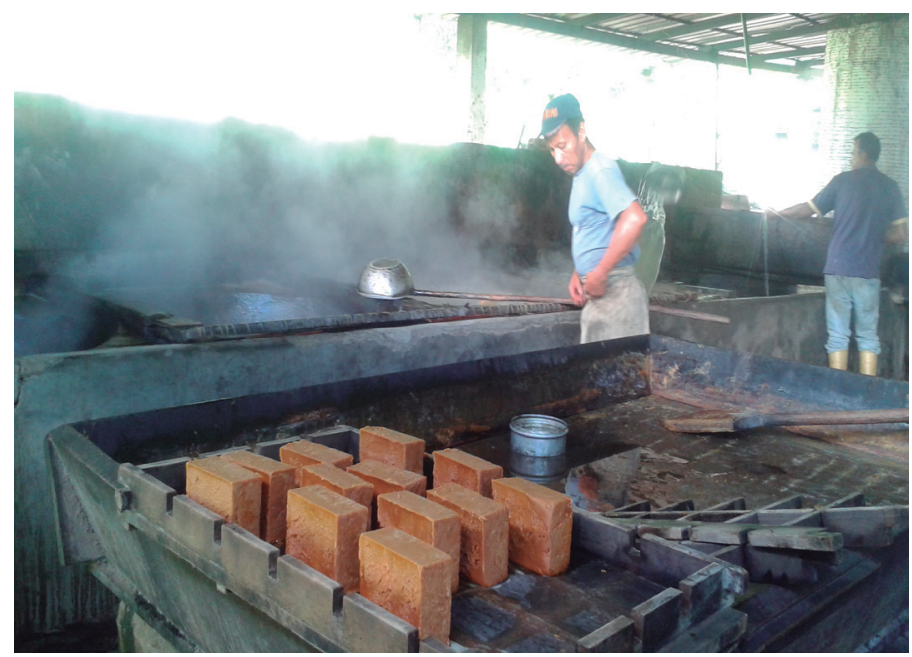

Fuente: Elaboración propia.

Figura 5. Plantación de caña panelera. Sector La Cordillera, parroquia San Juan de Lagunillas, Municipio Sucre, estado Mérida, Venezuela.

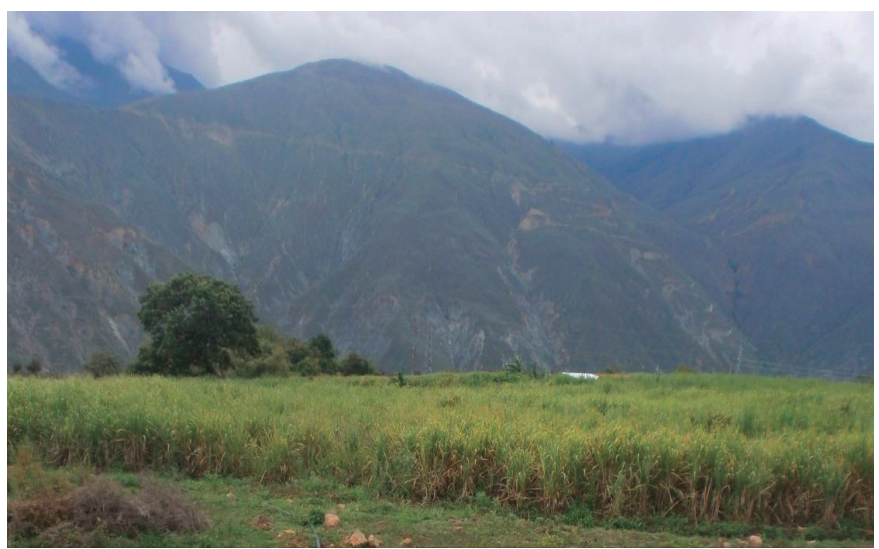

Fuente: Mogollón \& Peña (2014).

- $\quad$ Registro Único Obligatorio de Productoras y Productores Agrícolas (RUNOPPA) 
La información de la vocación agrícola que poseen las tierras es registrada periódicamente por el Ministerio del Poder Popular para la Agricultura Productiva y Tierras (MPPAPT), de acuerdo al decreto 047/2017 de fecha 17/10/2017 del referido ministerio. El mismo persigue entre otras cosas "disponer de datos y registros estadísticos directos de los productores primarios" (Gaceta Oficial \# 41.259, de fecha 18/10/2017). La certificación de un agricultor ante el RUNOPPA, consiste en que un técnico del referido ministerio debe acceder hasta la parcela y verificar que el agricultor, junto a su documento de identidad (C.I), está produciendo el rubro que él ha declarado.

- Base cartográfica de los registros agrarios del Instituto Nacional de Tierras (INTi).

La ley de tierras y desarrollo agrario contempla el reconocimiento y otorgamiento de los instrumentos agrarios, de manera que el agricultor usufructúe sus tierras y produzcan alimentos. Una vez el agricultor solicita el instrumento agrario, un técnico procede a realizar un levantamiento espacial de la perimetral de la parcela que ha sido solicitada para su regularización. Está información espacial es asociada, al documento de identidad del agricultor. Una vez verificado los procedimientos legales de rigor, el Instituto le otorga el instrumento agrario.

La base de datos cartográfica agroproductiva obtenida fue organizada en dos juegos de datos, una para el entrenamiento de la clasificación (áreas ROI), y la otra para la verificación de las áreas estimadas por la clasificación.

\subsubsection{Información espectral}

Todos los objetos de la tierra tienen la capacidad de interactuar con la energía. Dentro de estas interacciones esta la capacidad de reflejar o emitir la energía, la cual puede ser captada por los sensores remotos. Esta propiedad física hace que los elementos del paisaje como el suelo, el agua y la vegetación, tengan su identificación espectral característica, de acuerdo a sus propiedades físico-químicas. Entre estas propiedades, Guillen \& Dávila (2017) describen que para la vegetación; la reflectividad del infrarrojo (IR) próximo del espectro electromagnético depende, en gran medida, de la estructura anatómica de las hojas; tal como el número de capas celulares, el tamaño de las células y el espesor relativo del parénquima lagunar. Las hojas con mayor desarrollo del parénquima lagunar producen mayor 
dispersión (figura 6). Como consecuencia de ello, las hojas de dicotiledóneas presentan una mayor reflectividad que las de monocotiledóneas (caso de la caña de azúcar), aunque tengan el mismo espesor, ya que el parénquima lagunar de las primeras está más desarrollado. Los autores Guillen \& Dávila (2017) también describen que las hojas presentan una diferencia de comportamiento espectral entre el haz y el envés, ya que la reflectividad de este último es, generalmente, mayor, debido a la mayor presencia de los cloroplastos en el parénquima en empalizada. La presencia de vellosidad en la superficie foliar (hojas pubescentes), aumenta la reflectividad en el visible y en el IR medio, pero prácticamente no tiene influencia en el IR próximo.
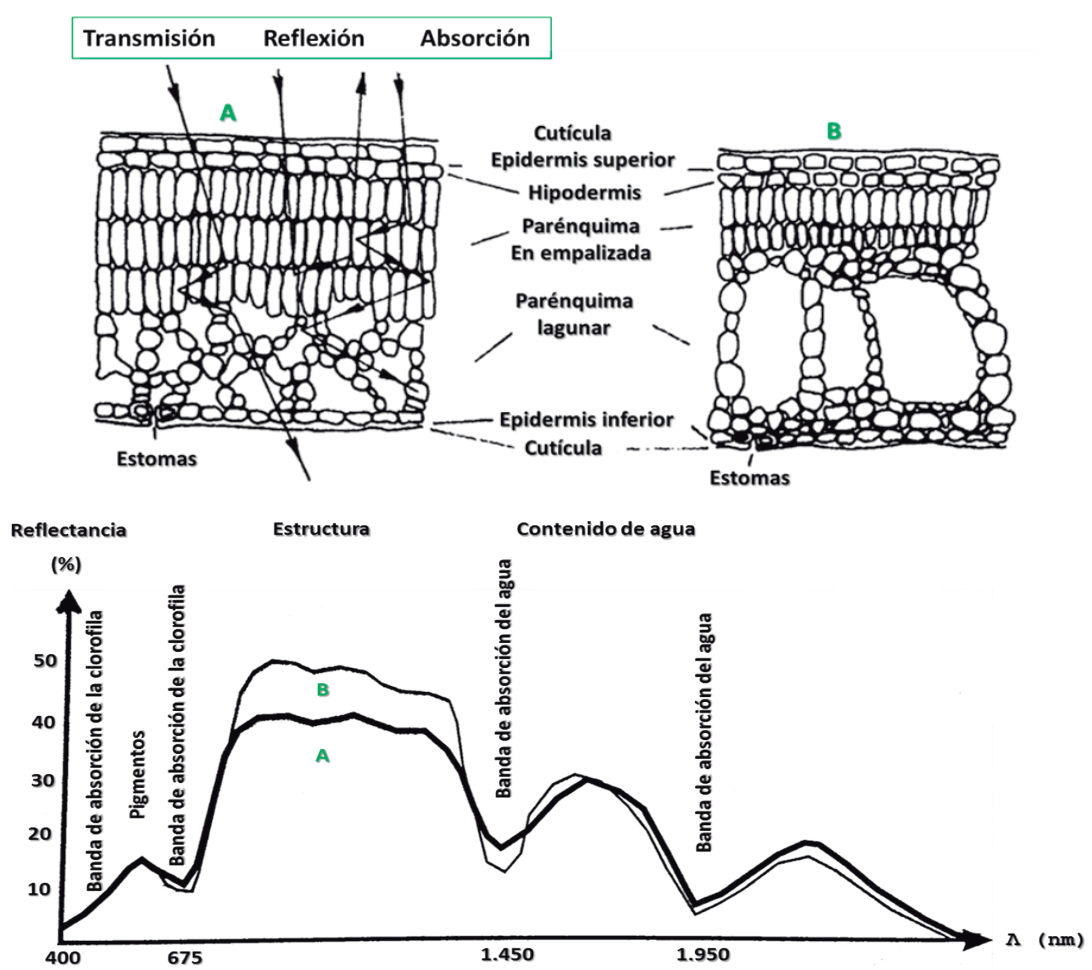

Figura 6. Influencia de la estructura interna de: hojas con un parénquima en empalizada muy desarrollada y el parénquima lagunar poco desarrollado (A), y con un parénquima en empalizada poco desarrollado y un parénquima lagunar muy desarrollado (B), sobre el comportamiento espectral. Modificado a partir de Girard \& Girard (2010). 
Las propiedades ópticas de las hojas varían en la fase juvenil y en su senescencia (figura 7). En esta última fase, el contenido en clorofilas decrece en favor de los carotenos, que producen colores rojizos y marrones, y de las xantofilas, que producen colores amarillentos. La desaparición de la clorofila y su sustitución por pigmentos marrones, produce un aumento de la reflectividad del amarillo-verde y del rojo. En el IR próximo, la reflectividad sólo varía cuando las hojas se secan y cambia su estructura interna. En el IR medio el aumento de la reflectividad foliar está relacionado con la perdida de agua, a estos efectos, debe considerarse que la disminución del contenido de humedad por el secado, comienza relativamente tarde, cuando la hoja ya está amarilla.

Figura 7. Reflectancia de las hojas con el proceso de senescencia. Adaptada de Santiago, O. (2006)

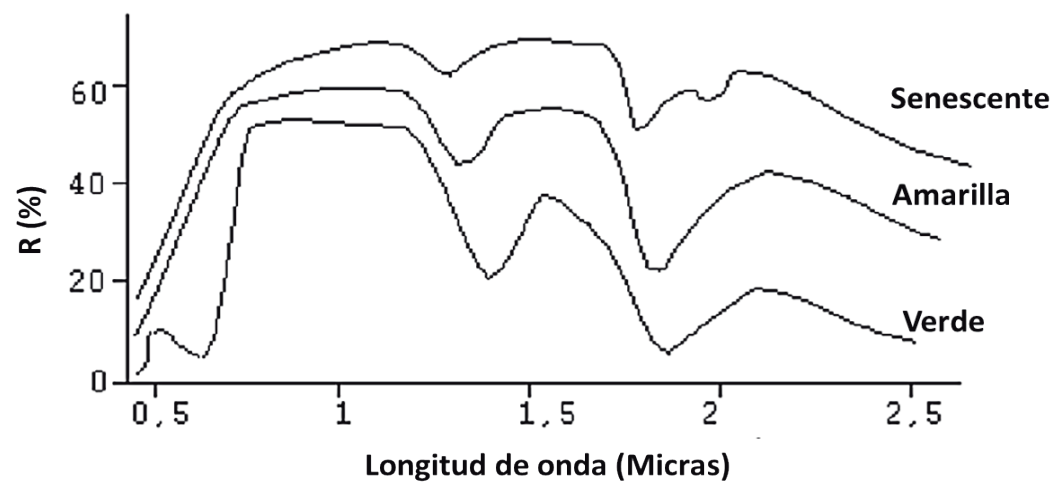

Las aplicaciones de los sensores remotos a cultivos de caña de azúcar (Saccharum officinarum) han tomado especial énfasis en el mapeo, clasificación y discriminación varietal (Gãlvao et al, 2005, Fortes y Demattê, 2006; Abdel-Rahman, E.M y Ahmed, F.B, 2008a; Apan, et al, 2018, Johnson, R. et al. 2008) y la estimación de la producción (Abdel-Rahman, E.M , 2010) y monitoreo del estatus fitosanitario y nutricional de las plantaciones (Abdel-Rahman, E.M, et al, 2008b, Miphokasap, P., et al, 2012). Los autores Murillo \& Carbonell (2012) señalan que la respuesta espectral del cultivo depende de cinco factores: la arquitectura del follaje, pigmentos de las hojas, el manejo agronómico, la geometría de adquisición y las condiciones atmosféricas. Dentro de ellos, los autores resaltan que la 
estructura geométrica es el factor más importante que afecta las propiedades ópticas del follaje de la caña. A su vez, Gãlvao et al (2005) y Fortes \& Demattê (2006), describen que el follaje medio erecto y abierto refleja más la energía que la de follaje erecto.

\section{- Imágenes Satelitales}

Para conocer los cambios y la dinámica espacio-temporal de las superficies de las unidades de producción de caña panelera, se obtuvieron imágenes de satélite SENTINEL 2A, con fechas del 27 de marzo de 2016 y del 01 de abril de 2017, adquiridas a través de la plataforma del servicio geológico del gobierno de los Estados Unidos (United States Geological Survey).

Estas imágenes cuentan con una resolución espacial de 10, 20 y 60 m; con 13 bandas espectrales que van desde las longitudes de ondas cortas para la detección de aerosoles, pasando por el visible y el infrarrojo. Cuentan con una resolución radiométrica de 16 bits, tiene un período de revisita cada 10 días, lo que permite obtener datos en tiempo real de la superficie terrestre, facilitando el seguimiento del crecimiento y desarrollo de los cultivos.

\subsection{Procesamientos digitales de las imágenes (PDI)}

Se realizó el procesamiento digital de las imágenes satelitales Sentinel 2A (2016 y 2017), el cual consiste en el procesamiento y mejoramiento de la calidad de los datos espaciales (radiométricos) para realizar la interpretación y extracción de la información de interés, empleando el software QGis versión 2.14.18.

\subsubsection{Corrección geométrica (georeferenciación)}

Se utilizó el mapa topográfico resultante de las cartas básicas de Cartografía Nacional de índices 5941-III-NE; 5941-III-NO; 5941-IV-SE, a escala 1:25.000. Seleccionando puntos de control identificables tanto en los vectores de referencia como en las imágenes de satélite, asignando un sistema de coordenadas estándar como lo es el Sistema de Referencia WG84 (World Geodetic System, 1984) y proyección cartográfica UTM zona 19N.

\subsubsection{Corrección radiométrica}

Este proceso permite determinar los niveles de reflectancia contenidos en los pixeles de la imagen, ya que los datos almacenados en una 
imagen cruda son valores o niveles digitales, los cuales no representan ninguna variable biofísica (Chuvieco, 2002b); por lo que es necesario realizar dicha conversión, puesto que el procedimiento de clasificación automatizada emplea los valores de reflectancia para identificar y categorizar las diferentes coberturas existentes.

\subsubsection{Corrección Atmosférica}

Este procedimiento consistió en eliminar o disminuir la influencia de los componentes de la atmósfera en la energía captada por el sensor, lo que permite mejorar la clasificación de las coberturas, especialmente, las áreas agrícolas. Empleando el método de sustracción de objetos obscuros, el cual consiste en restar a todos los valores digitales (VD) de cada banda su VD mínimo, situando el histograma en cero. Para ello, se empleó el plugín del software QGis versión 2.18.14 denominado Semi - Automatic Classification (SCP), siendo una herramienta útil para el procesamiento de las imágenes.

\subsubsection{Realce de las imágenes}

Se realizó a través de la técnica de mejoramiento lineal de contraste, logrando realzar detalles sutiles de la imagen, lo que a su vez permite mejorar la interpretación de los diferentes elementos contenidos en la misma. Con estos últimos procesos se logró obtener una mejor calidad visual de las imágenes satelitales.

\section{Clasificación digital de las imágenes}

El objetivo principal de la clasificación digital de imágenes es categorizar automáticamente todos los píxeles de una imagen en clases de cobertura de la tierra o clases específicas relacionadas a la interpretación que se esté llevando a cabo. Datos multiespectrales han sido usados normalmente para desarrollar estas clasificaciones, gracias a los patrones espectrales presentes en los datos para cada píxel, es decir, diferentes tipos de objetos manifiestan diferentes combinaciones de VD basados en sus propiedades de emitancia y reflectancia espectral (Guillén \& Dávila, 2017).

La clasificación supervisada requiere un conocimiento de la zona de estudio que permite delimitar sobre la imagen unas zonas o áreas representativas de las distintas categorías que se pretenden discriminar. Estas áreas se conocen como training fields (áreas de entrenamiento), ya que 
sirven para entrenar al software para que pueda reconocer las distintas categorías. A partir de estas áreas, el computador calcula diversos parámetros estadísticos de los VD que definen cada clase, para luego clasificar el resto de píxeles en una categoría determinada atendiendo a su radiometría. Para el presente trabajo se empleó la mitad del juego de datos de la base cartográfica agroproductiva obtenida del ítems 1.1.1, empleando el algoritmo de Máxima Probabilidad Gaussiana; clasificador que permitió describir dos categoría: cobertura del cultivo de caña panelera y otras coberturas, a través de la función de probabilidad, que utiliza la media y la desviación típica, por lo que la asignación de cada pixel a las categorías dependió de la mayor probabilidad de pertenencia que tengan (Chuvieco, 2002a).

\subsection{Validación}

Posterior a la clasificación digital, se realizó la validación de los resultados a través de tres pasos:

(a) La matriz de cambio con datos de interpretación visual de imágenes provenientes de SasPlanet.

(b) El grado de coincidencia de la estimación de la clasificación supervisada con las áreas previamente definidas como caña panelera en el segundo juego de datos de la base cartográfica agroproductiva.

(c) La Consulta a los técnicos expertos de las instituciones oficiales que laboran en el municipio Sucre y algunos pobladores de la zona, para identificar los ciclos y calendarios más probables de siembra y cosecha del rubro en la zona (figura 8).

Figura 8. Consulta a técnicos y pobladores de las zonas cañicultoras.

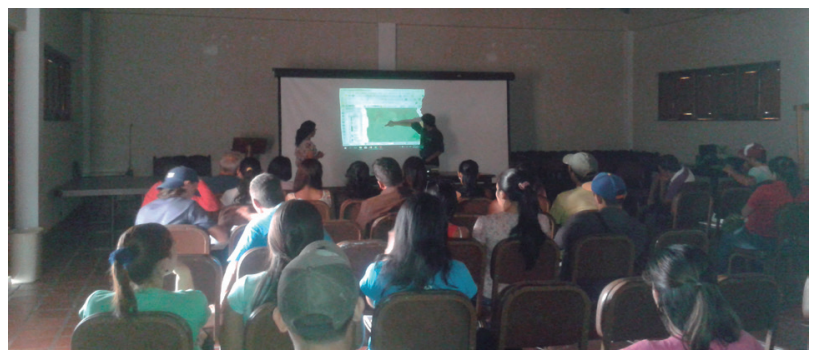

Fuente: Elaboración propia. 
Carlos Enrique Guillén-García - Amanda Mogollón -Rojo - Mirian Josefina Dávila-Albarrán - Katherina Boscán-Árraga Monitoring of panelera cane production using GIS and remote sensing tools, 2016-2017 years, Mérida, Venezuela

\section{Resultados}

\subsection{Base cartográfica agroproductiva}

Producto del cruce entre las bases de datos del RUNOPPA y los registros del INTI, se obtuvo para la parroquia San Juan de Lagunillas 74 registros con 12 rubros agrícolas: Apio, cambur, cebolla, lechosa, limón, mandarina, naranja, papa, pimentón, plátano, tomate y caña panelera. Estos rubros suman en su totalidad 467 ha, de las cuales, treinta y nueve (39) registros o parcelas corresponden a la caña panelera, que ocupan una superficie de 180 ha (figura 09).

Figura 9. Base cartográfica agroproductiva de la parroquia San Juan de Lagunillas, Todos los cultivos (izquierda). Parcelas de Caña panelera (derecha). Combinación de falso color (FCC) de la imagen de Sentinel

\section{A de fecha 27/03/2016.}
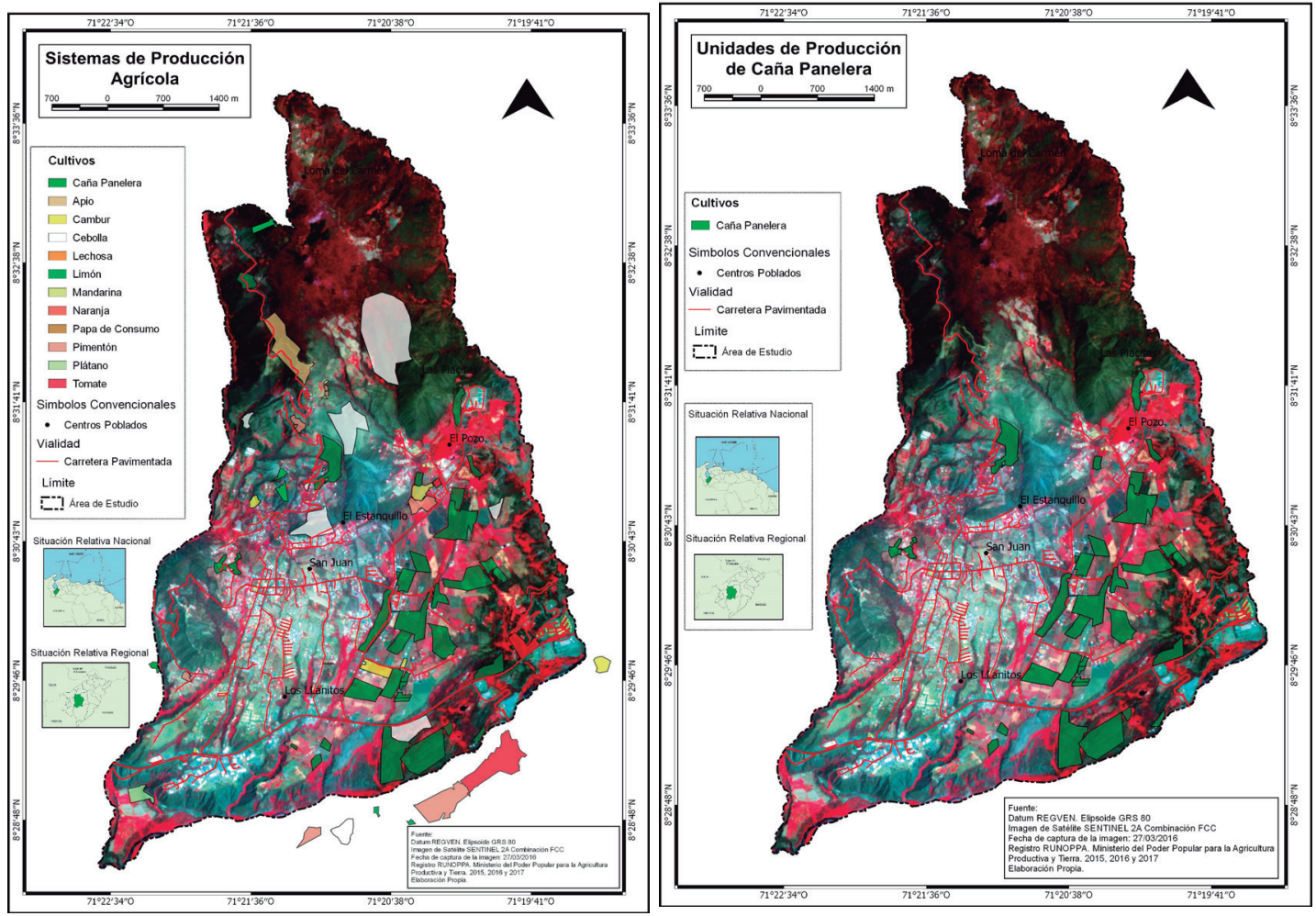
Carlos Enrique Guillén-García - Amanda Mogollón -Rojo - Mirian Josefina Dávila-Albarrán - Katherina Boscán-Árraga Monitoreo de la producción de caña panelera mediante herramientas de SIG y teledetección,

años 2016-2017, Mérida, Venezuela

Las parecelas de Caña panelera de la base cartográfica agroproductiva se dividieron de forma aleatoria en dos juegos de datos: 20 parcelas para el entrenamiento de la clasificación y 19 parcelas para la validación, como se aprecia en la figura 10.

Figura 10. Base cartográfica agroproductiva para áreas de entrenamiento y áreas de validación. Imagen Sentinel 2A de fecha 01/04/2017 al fondo.

Combinación de falso color (FCC).

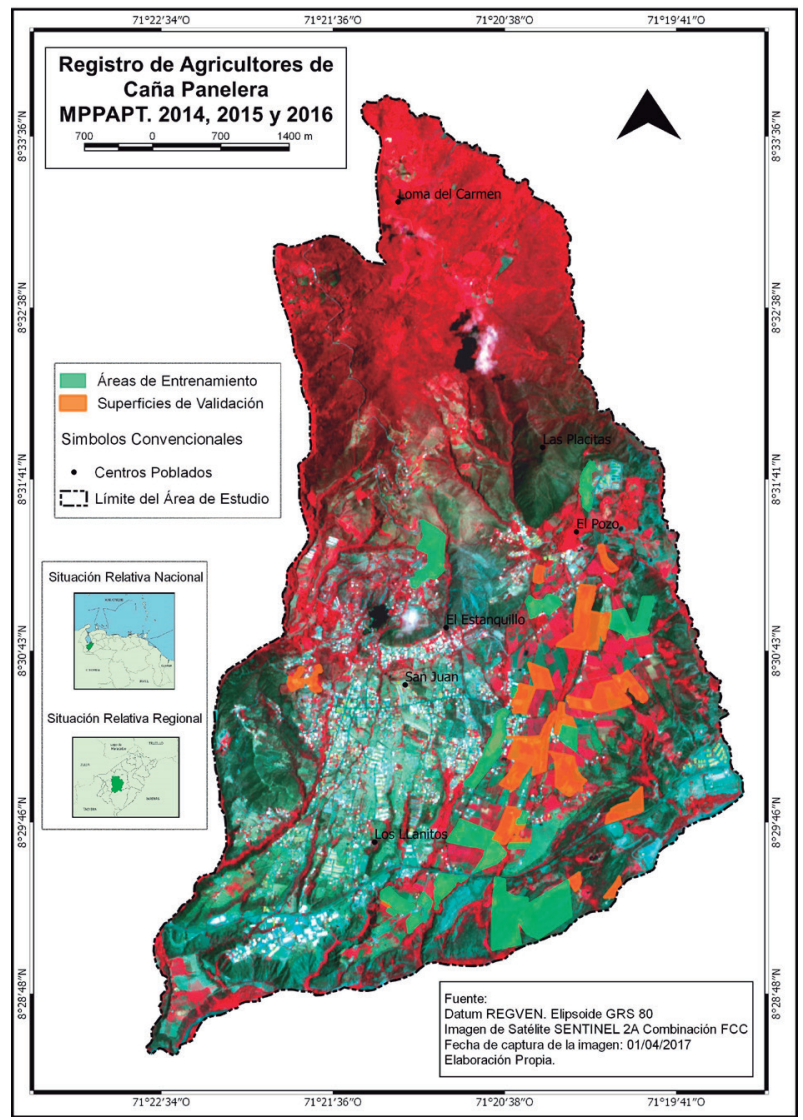

\subsection{Clasificación supervisada. Máxima probabilidad Gaussiana}

Para la categorización automática de la imagen, por medio del algoritmo de máxima probabilidad gaussiana, se establecieron dos categorías: Caña panelera y otras coberturas existentes en el área de estudio. De esta 
clasificación se obtuvo una superficie cultivada con caña panelera para el 27/03/2016 de 379,36 ha y para el 01/04/2017 un área de 361,37 ha (figura 11). Esta superficie estimada al multiplicarla por los rendimientos promedios de la caña en la zona de $80 \mathrm{Tm} / \mathrm{ha}$, obtendríamos $30.349 \mathrm{Tm}$ y 28.909 Tm de caña panelera para la primera y segunda fecha respectivamente. El resultado para el año 2016 supera en más de $50 \%$ la producción de caña panelera reportada por las instituciones oficiales del Estado encargadas de recabar dicha información, el cuál fue de 250 ha al cierre del año. Para el año 2017 la institución oficial aún no había consolidado la información, pero se estima que supere en gran proporción la cifra captada por las vías convencionales.

Figura 11. Clasificación supervisada a través del algoritmo de máxima probabilidad gaussiana. Año 2016 (izquierda) y año 2017 (derecha). Imágenes sobre el FCC de las imágenes procesadas correspondiente a cada año.

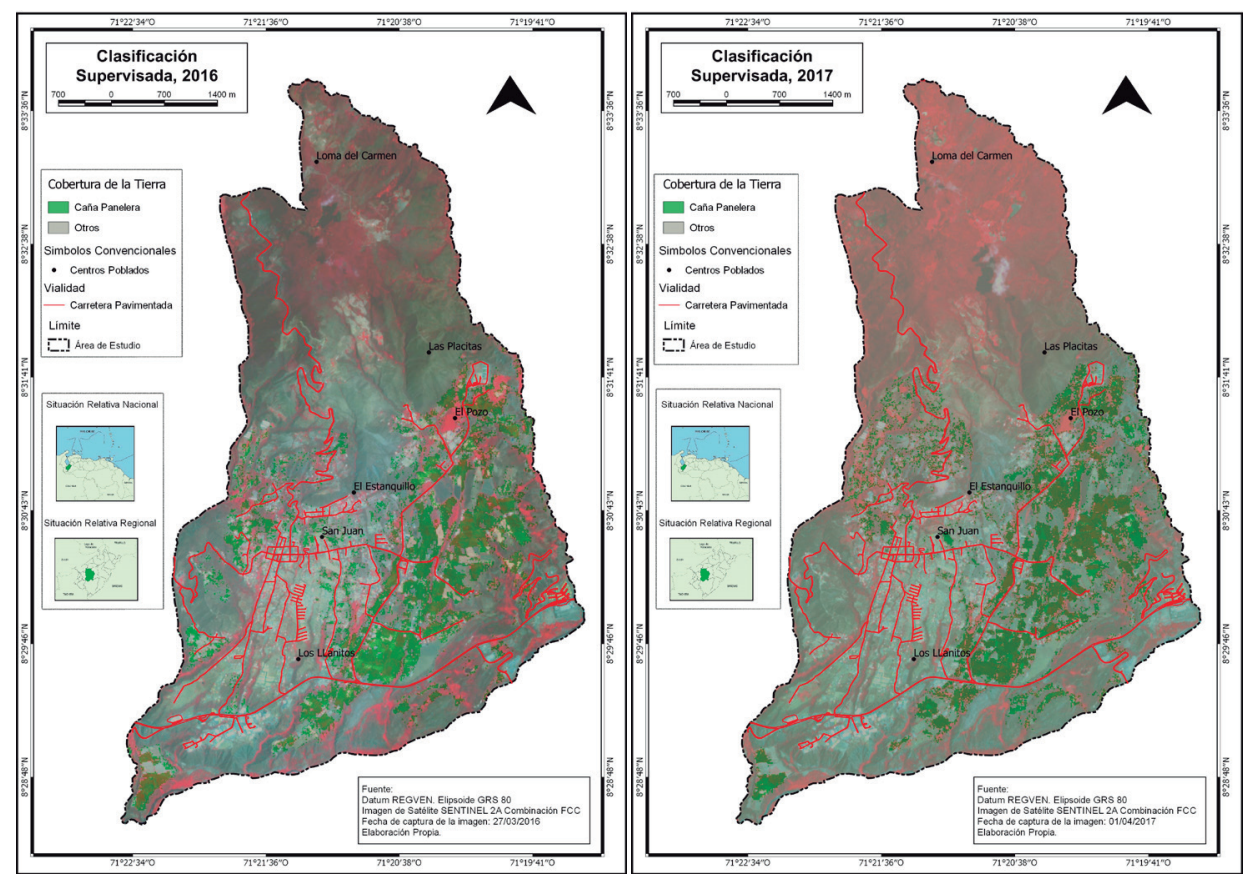


Carlos Enrique Guillén-García - Amanda Mogollón -Rojo - Mirian Josefina Dávila-Albarrán - Katherina Boscán-Árraga Monitoreo de la producción de caña panelera mediante herramientas de SIG y teledetección,

años 2016-2017, Mérida, Venezuela

\subsection{Proceso de Validación}

Los resultados obtenidos fueron objeto de dos procesos de validación, como una manera de evaluar la precisión con la cual el algoritmo de clasificación estima las superficies de caña panelera. Estas validaciones se describen a continuación.

- $\quad$ Base cartográfica agroproductiva.

Este proceso consistió en determinar el área que estima la clasificación dentro de los 19 polígonos (parcelas) predefinidos en la base agroproductiva con la vocación de uso de caña panelera. Esta validación arrojó que el algoritmo de máxima probabilidad gaussiana estimó de las 112,37 ha que ocupan las 19 parcelas de caña panelera; 81,91 ha (72 \%) y 84,47 ha (75\%) para los años 2016 y 2017 , respectivamente.

- Consulta a técnico expertos y pobladores del sector.

El segundo proceso de validación se basó en una consulta a los técnicos de las instituciones oficiales que laboran en la parroquia San Juan de Lagunillas, así como de algunos lugareños del sector. Ésta consistió en que los participantes, a través de una mesa de trabajo, evaluaran las áreas que han sido estimadas por la clasificación para los años 2016-2017; obteniéndose como resultados que para el 2016 la precisión, de acuerdo a los consultados es de $96 \%$ y para el 2017 de $99 \%$.

Las dos validaciones demuestran que la precisión de los algoritmos de clasificación para estimar las áreas cultivadas supera el $72 \%$, valor bastante aceptable en este tipo de estimaciones.

\section{Conclusiones}

La evaluación del sistema de producción de caña panelera en la parroquia San Juan de Lagunillas mediante algoritmos de clasificación, registros agrarios y base cartográfica de unidades de producción, ha demostrado que se puede estimar con gran precisión tanto la superficie como la producción de rubros agrícolas en grandes extensiones; inclusive se puede captar mayor información que los métodos convencionales que poseen las instituciones oficiales. Muestra de ello es que para el 2016, las clasificaciones identificaron 379 ha del cultivo caña panelera; resultados que representan más del $50 \%$ de la producción reportada por las instituciones del 
Estado (250 ha) encargadas de recabar dicha información. Para el 2017 los algoritmos de clasificaciones identificaron 361 ha, superficie que se estima superé en gran proporción la información captada de forma convencional por los organismos oficiales, ya que aún no se ha consolidado la cifra.

El monitoreo de rubros agrícolas a través de los SIG y la Teledetección genera información oportuna y veraz de superficies cultivadas, permitiendo conocer su localización, distribución espacial, comportamiento y evolución en distintos períodos de tiempo, elementos valiosos para la planificación y toma de decisiones. Esta información al ser gestionada mediante una infraestructura adecuada puede suministrar datos, información y las evaluaciones derivadas de estos, de manera eficiente a todos los actores productivos e institucionales vinculados al sector agroalimentario del Estado. Con estas herramientas se podrá hacer seguimiento y control a los planes de desarrollo agrícola, programas de financiamiento de la banca pública, proyectos y procesos productivos que se desarrollan en el sector.

\section{Referencias}

Abdel-Rahman, E.M y Ahmed, F.B, $\left(2008^{\mathrm{a}}\right)$. The application of remote sensing techniques to sugarcane (Saccharum spp. hybrid) production: a review of the literature. En International Journal of Remote Sensing. 29, (13), 3753-3767.

Abdel-Rahman, E.M, Ahmed, F.B, Van den Berg, M \& M.J. Way. (2008b).

Preliminary study on sugarcane Thrips (Fulmekiola serrata). Damage detection using imaging spectroscopy. P 287-289. En: Congress of South African Sugar Technologists' Association, 81. Proceeding. Durban. South African. 29-31 July. SASTA. Durban. South African. Abdel-Rahman, E.M. (2010). The potential for using remote sensing to quantify stress in and predict yield of sugarcane (Saccharum spp. hybrid). (Thesis submitted to the Faculty of Science and Agriculture, at the University of KwaZulu-Natal, in fulfillment of the requirements for the degree of Doctor of Philosophy in Environmental Sciences). Pietermaritzburg, South Africa. 206p.

Anindya S. (2016). Remote Sensing in Agriculture. En International Journal of Environment, Agriculture and Biotechnology (IJEAB). 1, (3). 362-367 p. 
Carlos Enrique Guillén-García - Amanda Mogollón -Rojo - Mirian Josefina Dávila-Albarrán - Katherina Boscán-Árraga Monitoreo de la producción de caña panelera mediante herramientas de SIG y teledetección,

años 2016-2017, Mérida, Venezuela

Butt, A., Shabbir, R., Ahmad, S., Aziz, N. (2015). Land use mapping and analysis using Remote Sensing and GIS: A case of study of Simly watershed, Islamabad, Pakistan. En The Egyptian Journal of Remote Sensing and Space Science. 18, 251-259.

Chen, Z. (2008). Monitoring and Management of Agriculture with Remote Sensing. In: Liang S. (Eds). En Advances in Land Remote Sensing. Springer, Dordrecht.

Chuvieco, E. (2002a). Fundamentos de Teledetección Espacial. Madrid, España: Rialp.

Chuvieco, E. (2002b). Teledetección Ambiental. La observación de la tierra desde el espacio. Barcelona, España: Ariel, S. A.

Farrell, M. \& Rivas, R. (2010). Estimación de Rendimiento en Girasol a Partir de Imágenes Captadas por el Sensor MODIS-TERRA. En Ciencia, 5, (19), 29.

Fortes, C. \& Demattê, J. A. M. (2006). Discrimination of sugarcane varieties using Landsat 7 ETM+ spectral data. En International Journal of Remote Sensing. 27, (7), 1.395 - 1.412.

Gaceta Oficial (G.O) de la República Bolivariana de Venezuela de fecha 18/10/2017. Decreto 047/2017 de fecha 17/10/2017 del Ministerio del Poder Popular para la Agricultura Productiva y Tierras (MPPAPT). Recuperado: http://www.tsj.gob.ve/gaceta-oficial

Gãlvao, L.S., Formaggio, A.R. \& Tisot, D.A. (2005). Discrimination of sugarcane varieties in Southeastern Brazil with EO-1 Hyperion data. Remote Sensing and Environment. 94, 523-534.

Girard, M-C. \& Girard, C-M. (2010). Traitement des données de télédétection. Paris, Francia: Dunod.

Guillén, C. \& Dávila, M. (2017). Guía teórica de Teledetección agrícola. Inventario de cultivos agrícolas. Diplomado en Teledetección y Sistemas de Información Geográfica aplicado a la Agricultura..

Instituto Geográfico Venezolano Simón Bolívar (IGVSM). (2014). Geoportal Nacional Simón Bolivar. Venezuela. Recuperado: http:// www.igvsb.gob.ve/

Johnson, R., Viator, R.P., Veremis, J.C., Richard, E.P. \& Zimba, P. V. (2008). Discrimination of sugarcane varieties with pigment profiles and high resolution, hyperspectral leaf reflectance data. En Journal of the American Society of Sugar Cane Technologists. 28, 63-75. 
Kaliraj, S., Chandrasekarb, N., Ramachandrana, K., Srinivasb, Y., \& Saravanan, S. (2017). Coastal landuse and land cover change and transformations of Kanyakumari coast, India using remote sensing and GIS. En the Egyptian Journal of Remote Sensing and Space Sciences. Article in press.

Martínez, F. (1963). Estudio Integral de la Cuenca del Chama; Sector Lagunillas de Urao. Instituto de Geografía y Conservación de Recursos Naturales. Universidad de los Andes. Mérida, Venezuela.

Miphokasap, P., Honda, K., Vaiphasa, C., Souris, M., \& Nagai, M. (2012).

Estimating Canopy Nitrogen Concentration in Sugarcane Using Field Imaging Spectroscopy. En Remote Sensing.4, 1.651-1.670.

Mosquera, S., Carrera, J. \& Villada, H. (2007). Variables que Afectan la Calidad de la Panela Procesada en el Departamento del Cauca. Facultad de Ciencias Agropecuarias, 5(1),18.

Quantum GIS Development Team. Quantum GIS Geographic Information System, Open Source Geospatial Foundation (2009). Recuperado: http://qgis.osgeo.org.

Rojas, J. (1970). El Paisaje Semiárido de la Cuenca Media del Río Chama (Andes Venezolanos). (Trabajo Especial de Grado. Escuela de Geografía. Universidad de Los Andes). Mérida Venezuela.

Santiago, O. (2006). Teledetección fundamental. $3^{\text {a }}$ edición. Escuela técnica superior de ingenieros en topografía, geodesia y cartografía. Universidad politécnica - Madrid.

USGS. United States Geological Survey. (2017). Recuperado: https://earthexplorer.usgs.gov/ 